УДК 519.876.2:336

${ }^{[0000-0003-2474-7697]}$ Т. В. Нескородева, к.т.н., дочент, зав. кафедры

e-mail: t.neskorodieva@donnu.edu.ua

Донецкий национальный университет имени Васыля Стуса

ул. 600-летия, 21, г. Винница, 21027, Украина

\title{
ПОСТАНОВКА ЗАДАЧ ПОДСИСТЕМЫ АУДИТА ПРЕДПОСЫЛКИ СРЕДНЕГО УРОВНЯ ИТ СППР
}

В статье рассматривается проблема постановки задач подсистем аудита предпосылки Положений (стандартов) бухгалтерского учета в ИТ СППР как составляющих методики обобщенно-множественного отображения информации. Выделены два типа структурных элементов аудита среднего уровня, инвариантных относительно особенностей предприятия: множество объектов и операчий. Это позволило определить структурные элементы информачионной модели предметной области: данные, характеризующие множество объектов, $и$ данные, характеризующие множество операџий. Сформирована функциональная структура преобразований множеств данных в виде последовательности отображений, подчиненных правилам предпосылки «Полнота». Выделены два типа отображений по их функииональному назначению, первое из которых характеризует преобразование в подсистеме учета множества объектов, второе - характеризует преобразование данных при их передаче между подсистемами. Выделены два типа элементарных подзадач аудита предпосылки. Это позволяет декомпозировать задачу автоматизации проверки предпосылки «Полнота» на задачи проверки эквивалентности двух типов отображений.

Ключевые слова: постановка задачи аудита, информационная технология, СППР аудита, отображение множеств, средний уровень.

Введение. В настоящее время актуальной научно-технической проблемой информационных технологий финансово-экономической сферы является автоматизация анализа больших объемов данных финансовоэкономической информации предприятий, хранящихся и поступающих в режиме онлайн в базы данных локальных и глобальных компьютерных систем с целью формирования рекомендаций принятия решений при аудите [1-5].

Например, эффективность ИТ-бизнеса в снижении коррупции обоснована в [1]. В [2] обсуждаются теоретические и практические вопросы использования ИТ в аудиторской сфере. Определены изменения, которые вносит в методологии аудита его комплексная компьютеризация.

Применение современных систем бухгалтерского учета и управления на предприятии, интегрированных в глобальные, многоуровневые системы информационных компьютерных сетей, предоставляет потенциальные возможности обработки больших объемов данных, которые используются не в полном объеме [3]. В [4] представлены архитектуры подсистем внешней и внутренней системы аудита Аудит 4.0, функционирование и экс- плуатация которых сталкиваются с проблемой обработки больших объемов данных. Также сегодня в практических и научных источниках, которые изучают проблемы и перспективы развития аудита, рассматривается возможность принятия законодательных актов, которые позволят использовать аналитические доказательства (в том числе противоречивости данных), полученные при анализе больших объемов данных, в качестве основы для судебных решений без документального изучения первичных документов [5]. Это свидетельствует о том, что тематика исследования, которая касается проектирования ИТ-аудита, является актуальной.

Анализ последних исследований. При проектировании ИТ-аудита необходимо предполагать возможность их применения к финансово-экономическим данным предприятий различных отраслей, видов производства различной организационной структуры и ИТ учета. Экономико-производственная деятельность и ИТ предприятия образуют сложную социально-экономическую и техническую систему. Эта система как объект аудита характеризуется глобальной многоуровневой иерархической структурой гетерогенных, многофакторных, многофункциональных 
взаимосвязей, взаимозависимостей и взаимодействий ее подсистем с ИТ контроля, учета, управления, ведения бизнеса, с другими ИТ и системами в структуре информационной системы национальной экономики. В то же время данные на каждом уровне имеют сетевую структуру. Современная методология прикладного системного анализа не соответствует этим требованиям [10]. Поэтому проблема разработки методологических основ ИТаудита является актуальной.

В [11] обосновывается необходимость атрибутивной выборочной проверки документов даже при полной автоматизации учета на основании статистического подхода к формированию аудиторской выборки. Представленная методика атрибутивного выборочного исследования позволяет определить объем выборки и верхнюю границу точности. Однако остается открытым вопрос о методике тестирования по каждой группе документов и взаимосвязанным группам документов (последовательных операций). Также указывается, что в силу того, что хозяйственные операции и первичные документы формируются с помощью программ, поэтому ошибки, связанные с расчетом сумм, практически исключены. В то же время тестирование необходимо применять с целью выяснения, имели ли действительно место факты хозяйственной деятельности, учтены ли они в БД компьютерной программы учета. Однако не выполнена формальная постановка данной задачи, а также задачи выявления признаков существования фактов хозяйственной деятельности, которые имели место и не учтены в БД.

В работе [12] представлена методика обобщенно-множественного отображения информации в подсистеме экспресс-аудита предпосылки «Соответствие расходов и доходов» на среднем уровне. В случае выявления неэквивалентных подмножеств данных система переключается (через ЛПР) на подсистему аудита предпосылки «Полнота», которая предполагает, что все операции, которые были реально выполнены, учтены в отчётности.

Говоря об автоматизации процедур анализа, следует отметить, что в литературе представлены методы обнаружения мошенничества, основанные на применении моделей нейронных (вероятностных) сетей, логистических регрессий, деревьев решений, экспертных оценок, статистических методов анализа данных [6-9]. Применение данных методов позволяет анализировать отдельные пока- затели или выявлять аномальные значения. Их применение дает результат, если выполняются определенные условия, которые зависят от свойств показателя, т. е. они не являются универсальными, что затрудняет автоматизацию анализа на их основании и их использование при решении задач автоматизации на всех этапах аудита. Следовательно, актуальной является задача создания методики извлечения и подготовки данных, которая позволит реализовывать их автоматический анализ для задач аудита.

Проектирование ИТ СППР согласно методике обобщенно-множественного отображения информации, предложенной в [12], требует выделения отображений множеств для декомпозиции задачи проверки предпосылки на элементарные задачи.

Цель статьи - выполнить постановку задач аудита предпосылки на среднем уровне для автоматизированного их решения в информационной технологии системы поддержки принятия решений (ИТ СППР), инвариантную относительно особенностей предприятия как составляющих методики обобщенномножественного отображения информации при проектировании ИТ.

Для этого необходимо решить следующие задачи:

1) сформировать структуру предметной области проверки среднего учета, инвариантную относительно особенностей предприятия;

2) определить виды взаимосвязей между элементами предметной области среднего учета, подчиненные правилам предпосылки;

3) выделить особенности учета данных элементов и взаимосвязей между ними в подсистемах среднего уровня учета;

4) выполнить постановку задач аудита предпосылки на среднем уровне для автоматизированного их решения в подсистеме аудита предпосылки.

Проиллюстрируем методику среднего уровня на примере данных предметной области аудита предпосылки «Полнота» материальных расходов. Рассмотрим случай преобразования сырья в полупродукт, а затем в продукт при последовательной обработке в цехах в случае безвозвратных отходов.

Изложение основного материала. Учет характеристик материальных расходов в подсистеме среднего уровня осуществляется по каждому цеху (последовательности цехов) за плановые периоды (месяц, квартал, год). Экономико-производственные объекты учета, 
сопровождающие материальные расходы: сырье, полупродукт, брак, отходы, готовая продукция, незавершенное производство. Операции, которые характеризуют преобразование данных объектов учета, - производственные операции.

Данные среднего уровня, которые характеризуют предметную область аудита материальных расходов, зависят от:

1) обобщенных характеристик множеств объектов, преобразование которых сопровождает производственные операции;

2) обобщенных характеристик множеств производственных операций;

3) взаимосвязей между обобщёнными характеристиками множеств объектов и производственных операций, характеризующих правила предпосылки;

4) функциональных особенностей системы среднего уровня.

Следовательно, для постановки задач аудита, инвариантной относительно особенностей предприятия, необходимо формализовать:

1) множества объектов учета, преобразование которых сопровождает производственные операции;

2) множества производственных операций;

3) взаимосвязи между множествами объектов учета и производственных операций;

4) функциональные особенности учета обобщенных характеристик множеств данных и взаимосвязей между ними в системе среднего уровня;

5) сформировать функциональную структуру отображений множеств, проверка эквивалентности которых составляет задачу аудита Предпосылки (стандарта) бухгалтерского учета (П(с)БУ).

В соответствии с предложенными правилами обозначим:

$E$ - множество объектов учета, преобразование которых сопровождает производственные операции за период $T$,

$X$ - множество производственных операций за период $T$.

На основании анализа структуры системы учета материальных расходов выделим множества объектов учета (таблица 1) и множества операций материальных расходов (таблица 2). При учете материальных расходов в течение периода $T$ между объектами учета и операций выделенных множеств (таблицы 1, 2) формируются множества взаимосвязей, эле- менты которых формализованы на первом уровне в виде отношений соответствия $r^{+}$и $r^{-}$операций увеличения и уменьшения объекта учета соответственно [13].

Таблица 1 - Множества объектов материальных расходов (за период $T$ ) (последовательная схема цехов)

\begin{tabular}{|c|c|}
\hline \multicolumn{2}{|c|}{ Множество объектов учета } \\
\hline Обозначение & Название \\
\hline$E_{2}$ & Сырье \\
\hline$E_{3}$ & Производство (цех 1) \\
\hline$A_{1}$ & Полупродукт (цех 1) \\
\hline$B_{1}$ & $\begin{array}{l}\text { Невозвратные отходы } \\
\text { (цех 1) }\end{array}$ \\
\hline$C_{1}$ & Брак (цех 1) \\
\hline$D_{1}$ & $\begin{array}{l}\text { Незавершенное произ- } \\
\text { водство (цех 1) }\end{array}$ \\
\hline$E_{4}$ & Производство (цех 2) \\
\hline$A_{2}$ & Готовая продукция (цех 2) \\
\hline$B_{2}$ & Отходы (цех 2) \\
\hline$C_{2}$ & Брак (цех 2) \\
\hline$D_{2}$ & $\begin{array}{l}\text { Незавершенное произ- } \\
\text { водство (цех 2) }\end{array}$ \\
\hline$E_{5}$ & Готовая продукция \\
\hline
\end{tabular}

Формализуем отношения соответствия множеств параллельно-последовательных операций в виде графа $G_{1}^{(c)}$ (рисунок 1):

$$
\begin{gathered}
G_{1}^{(c)}=\left(V_{1}^{(c)}, R_{1}^{(c)}\right), V_{1}^{(c)}=(X, Y, E), \\
R_{1}^{(c)}=\left(r^{+(c)}, r^{-(c)}\right),
\end{gathered}
$$

где $G_{1}^{(c)}$ - граф множеств параллельнопоследовательных операций,

$V_{1}^{(c)}$ - множество вершин графа $G_{1}^{(c)}$,

$R_{1}^{(c)}$ - множество ребер графа $G_{1}^{(c)}$,

$E$ - вершина, характеризующая множество объектов,

$X$ и $Y$ - вершины, характеризующие множества операций,

$$
r^{+(c)} \text { и } r^{-(c)}-\text { ребра, характеризующие }
$$

отношения соответствия к увеличению и уменьшению множества объектов учета соответственно. 


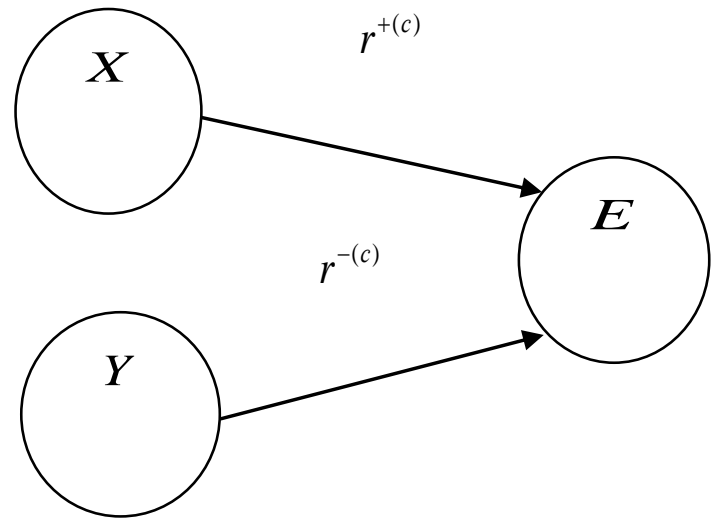

Рисунок 1 - Граф $G_{1}^{(c)}$ отношения соответствия множеств операций и множества объектов учета

Для множества объектов и операций материальных расходов данные отношения представлены в таблице 3 .

Отношение соответствия $G_{1}^{(c)}$ порождает отображение соответствующих множеств данных $X \rightarrow Y$. Проверка эквивалентности множеств при данном отображении составляет задачу первого типа.

Для формализации множеств объектов учета, взаимосвязанных с множеством операцией, выделим два объекта, первый из которых уменьшается при операции $x$, а второй увеличивается. Согласно экономическому смыслу операции данные объекты должны быть разных видов. Формализуем данные соотношения.

Два множества объектов учета $E_{s}$ и $E_{s+1}$ определяются как взаимосвязанные с множеством параллельно-последовательных операций $X$, если они удовлетворяют условию:

$$
\begin{array}{r}
\forall x \in X\left(\exists e_{s} \in E_{s}: x r^{-} e_{s}\right) \wedge \\
\wedge\left(\exists e_{s+1} \in E_{s+1}: x r^{+} e_{s+1}\right),
\end{array}
$$

где $E$ - множество объектов учета,

$s$ и $s+1$ - переменные, характеризующие виды множеств объектов учета,

$X$ - множество операций,

$r^{+}$- отношение соответствия операции к увеличению объекта учета, $r^{-}$- отношение соответствия операции к уменьшению объекта учета.

Формализуем соотношения (2) в виде графа $G_{2}^{(c)}$ (рисунок 2):

$$
\begin{aligned}
& G_{2}^{(c)}=\left(V_{2}^{(c)}, R_{2}^{(c)}\right), V_{2}^{(c)}=\left(X, E_{s}, E_{s+1}\right), \\
& R_{2}^{(c)}=\left(r^{-(c)}, r^{+(c)}\right),
\end{aligned}
$$

где $G_{2}^{(c)}$ - граф отношения соответствия множества операций и объектов учета,

$V_{2}^{(c)}$ - множество вершин графа $G_{2}^{(c)}$,

$R_{2}^{(c)}$ - множество ребер графа $G_{2}^{(c)}$,

$E$ - вершина, характеризующая множество объектов учета,

$s$ и $s+1$ - номера, характеризующие виды множеств объектов учета,

$X$ - вершина, характеризующая множество операций,

$r^{+(c)}$ - ребро, характеризующее отношение соответствия к увеличению множества объектов учета,

$r^{-(c)}$ - ребро, характеризующее отноше-

ние соответствия к уменьшению множества объектов учета.

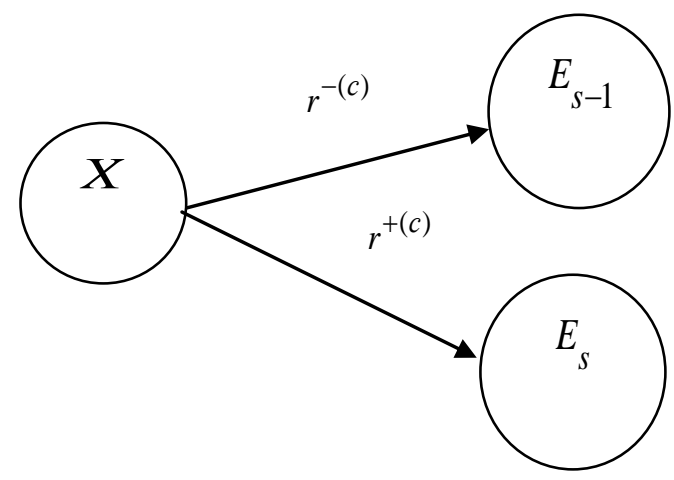

$$
\begin{gathered}
\text { Рисунок } 2 \text { - Граф } G_{2}^{(c)} \text { отношений } \\
\text { соответствия множества операций } \\
\text { и объектов учета }
\end{gathered}
$$

Отношение соответствия $G_{2}^{(c)}$ порождает отображение соответствующих множеств данных. Проверка эквивалентности множеств при данном отображении составляет задачу второго типа. 
Таблица 2 - Данные множеств операций материальных расходов (за период $T$ ) (последовательная схема цехов)

\begin{tabular}{|c|c|c|}
\hline \multicolumn{2}{|r|}{ Множество операций } & \multirow{2}{*}{$\begin{array}{c}\text { Характеристика данных множества } \\
\text { операций }\end{array}$} \\
\hline Обозначение & Название & \\
\hline$X_{3}$ & $\begin{array}{l}\text { Получение и списание (бухгал- } \\
\text { терия) сырья на производство }\end{array}$ & $\begin{array}{l}\text { Обобщенные показатели получения сырья } \\
\text { на производство по накладным- } \\
\text { требованиям (НT) }\end{array}$ \\
\hline$X_{4}$ & $\begin{array}{l}\text { Выпуск полупродукта (отходы } 1, \\
\text { брак 1, незавершенное произ- } \\
\text { водство 1) }\end{array}$ & $\begin{array}{l}\text { Обобщенные показатели выпуска полу- } \\
\text { продукта из цеха 1, отходов, брака, неза- } \\
\text { вершенного производства }\end{array}$ \\
\hline$X_{4(1)}$ & $\begin{array}{l}\text { Производство полупродукта } \\
\text { (цех 1) }\end{array}$ & $\begin{array}{l}\text { Обобщенные показатели выпуска полу- } \\
\text { продукта из цеха } 1\end{array}$ \\
\hline$X_{4(2)}$ & Списание отходов (цех 1) & $\begin{array}{l}\text { Обобщенные показатели списания отхо- } \\
\text { дов из цеха } 1\end{array}$ \\
\hline$X_{4(3)}$ & Списание брака (цех 1) & $\begin{array}{l}\text { Обобщенные показатели списания брака } \\
\text { из цеха } 1\end{array}$ \\
\hline$X_{4(4)}$ & $\begin{array}{l}\text { Инвентаризация незавершенного } \\
\text { производства (цех 1) }\end{array}$ & $\begin{array}{l}\text { Обобщенные показатели незавершенного } \\
\text { производства из цеха } 1\end{array}$ \\
\hline$X_{5}$ & $\begin{array}{l}\text { Выпуск (оприходование) гото- } \\
\text { вой продукции (отходов, брака, } \\
\text { незавершенного производства) }\end{array}$ & $\begin{array}{l}\text { Обобщенные показатели выпуска готовой } \\
\text { продукции (ГП), отходов, брака, незавер- } \\
\text { шенного производства на складе и бухгал- } \\
\text { терии }\end{array}$ \\
\hline$X_{5(1)}$ & $\begin{array}{l}\text { Производство готовой продук- } \\
\text { ции (цех 2) }\end{array}$ & $\begin{array}{l}\text { Обобщенные показатели выпуска полу- } \\
\text { продукта из цеха } 2\end{array}$ \\
\hline$X_{5(2)}$ & Списание отходов (цех 2) & $\begin{array}{l}\text { Обобщенные показатели списания отхо- } \\
\text { дов из цеха } 2\end{array}$ \\
\hline$X_{5(3)}$ & Списание брака (цех 2) & $\begin{array}{l}\text { Обобщенные показатели списания брака } \\
\text { из цеха } 2\end{array}$ \\
\hline$X_{5(4)}$ & $\begin{array}{l}\text { Незавершенное производство } \\
\text { (цех 2) }\end{array}$ & $\begin{array}{l}\text { Обобщенные показатели незавершенного } \\
\text { производства из цеха } 2\end{array}$ \\
\hline
\end{tabular}

Отношения соответствия взаимосвязанных множеств объектов учета на примере материальных расходов (таблица 1) по отношению к множеству операций (таблица 2), формализованные в виде графа $G_{2}^{(c)}$, представлены в таблице 4. Последовательность двух видов отношений соответствия схематически представлена на рисунке 3.

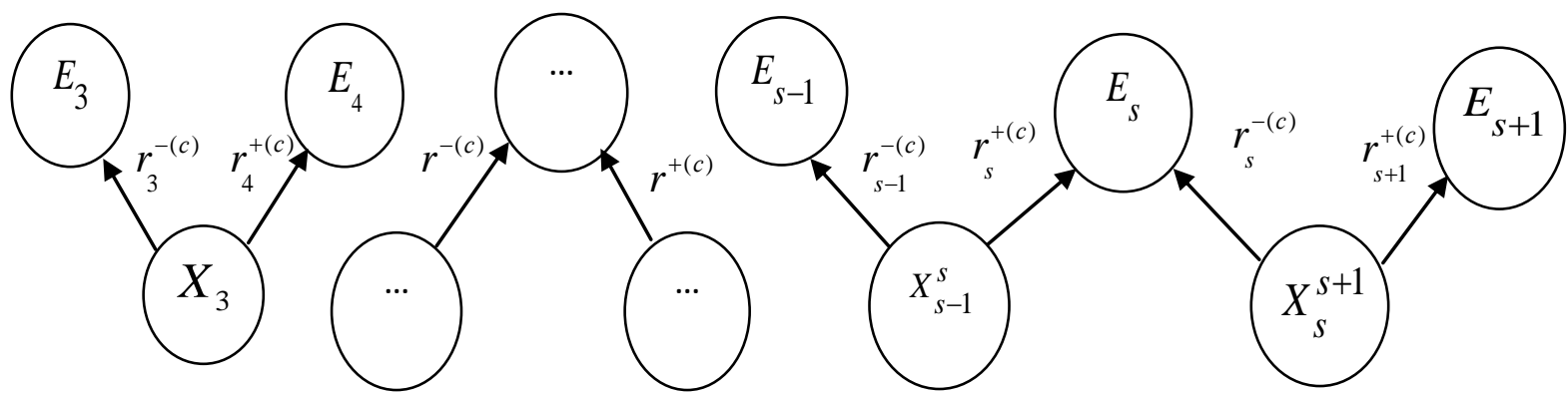

Рисунок 3 - Граф $G_{3}^{(c)}$ отношений соответствия обобщенных множеств параллельнопоследовательных операций и объектов учета, которые преобразуются за период $T$ 
Таблица 3 - Отношения соответствия множеств операций и объектов учета за период $T$ (последовательная схема цехов, безвозвратные отходы)

\begin{tabular}{|c|c|c|}
\hline \multirow{2}{*}{$\begin{array}{c}\text { Множество объектов } \\
\text { учета } E\end{array}$} & \multicolumn{2}{|c|}{$\begin{array}{l}\text { Отношения соответствия множеств данных } \\
\text { операций к множеству объектов } E\end{array}$} \\
\hline & соответствия увеличения $r^{+(c)}$ & соответствия уменьшения $r^{-(c)}$ \\
\hline $\begin{array}{c}E_{3} \\
\text { Производство (цех 1) }\end{array}$ & $\begin{array}{c}X_{3} \\
\text { Отпуск сырья в производство }\end{array}$ & $\begin{array}{c}X_{4} \\
\text { Общий выпуск полупродукта, от- } \\
\text { ходов, брака и незавершенного } \\
\text { производства }\end{array}$ \\
\hline $\begin{array}{c}A_{3} \\
\text { Полупродукт (цех 1) }\end{array}$ & \multirow{4}{*}{$\begin{array}{c}X_{3} \\
\text { Отпуск сырья в производство } \\
\text { за период } T\end{array}$} & $\begin{array}{c}X_{4(1)} \\
\text { Выпуск полупродукта (цех 1) }\end{array}$ \\
\hline $\begin{array}{c}B_{3} \\
\text { Отходы (цех 1) }\end{array}$ & & $\begin{array}{c}X_{4(2)} \\
\text { Списание сырья на отходы (цех 1) }\end{array}$ \\
\hline $\begin{array}{c}C_{3} \\
\text { Брак (цех 1) }\end{array}$ & & $\begin{array}{c}X_{4(3)} \\
\text { Списание сырья на брак (цех 1) }\end{array}$ \\
\hline $\begin{array}{c}D_{3} \\
\text { Незавершенное про- } \\
\text { изводство (цех 1) }\end{array}$ & & $\begin{array}{c}X_{4(4)} \\
\text { Инвентаризация незавершенного } \\
\text { производства (цех 1) }\end{array}$ \\
\hline $\begin{array}{c}E_{4} \\
\text { Производство (цех 2) }\end{array}$ & $\begin{array}{c}X_{4(1)} \\
\text { Оприходование полупродукта } \\
(\text { цех 1) }\end{array}$ & $\begin{array}{c}X_{5} \\
\text { Выпуск готовой продукции }\end{array}$ \\
\hline$\ldots$ & $\ldots$ & $\ldots$ \\
\hline $\begin{array}{c}E_{5} \\
\text { Готовая продукция }\end{array}$ & $\begin{array}{c}X_{5} \\
\text { Оприходование готовой } \\
\text { продукции }\end{array}$ & $\begin{array}{c}\text { Доход от реализации готовой } \\
\text { продукции }\end{array}$ \\
\hline
\end{tabular}

Обозначим:

$N_{s}$ - множество номеров документов первого уровня, в которых учтены данные множества операций $X_{s-1}^{s}$,

$x\left(n_{s}^{(c)}\right)$ - данные среднего уровня множества операций $X_{s-1}^{s}\left(N_{s}\right)$,

$e\left(n_{s}^{(c)}\right)$ - данные среднего уровня множества объектов учета $E\left(N_{s}\right)$.

Тогда последовательность отношений множеств операций и объектов учета $G_{3}^{(c)}$ порождает последовательность отображений множеств данных объектов учета и операций: $e\left(n_{1}^{(c)}\right) \rightarrow e\left(n_{2}^{(c)}\right) \rightarrow \ldots \rightarrow e\left(n_{s}^{(c)}\right) \rightarrow e\left(n_{s+1}^{(c)}\right)$,

$$
x\left(n_{1}^{(c)}\right) \rightarrow x\left(n_{2}^{(c)}\right) \rightarrow \ldots \rightarrow x\left(n_{s}^{(c)}\right) \rightarrow x\left(n_{s+1}^{(c)}\right) .
$$

На основании методики обобщенномножественного отображения информации при формировании методики проектирования подсистемы аудита предпосылки «Полнота» выделим следующие две локальные подзадачи.

Первая задача - определение эквивалентных и неэквивалентных подмножеств при отображении обобщенных показателей среднего уровня учета $e\left(n_{s}^{(c)}\right)$ и $e\left(n_{s+1}^{(c)}\right)$ множеств объектов $E_{s}$ и $E_{s+1}$ двух видов (или подвидов, рисунок 4), взаимосвязанных множеством параллельных операций $X_{s}^{s+1}\left(N_{s}\right)$ за период проверки $T$. 
Таблица 4 - Отношения соответствия множеств объектов учета и операций за период $T$ (последовательная схема цехов, безвозвратные отходы)

\begin{tabular}{|c|c|c|}
\hline \multirow{2}{*}{ Множество операций } & \multicolumn{2}{|c|}{$\begin{array}{l}\text { Отношения соответствия множеств объектов } E_{s-1} \text { и } \\
\qquad E_{s} \text { к множеству операций }\end{array}$} \\
\hline & $\begin{array}{c}\text { соответствие } \\
\text { уменьшения } r^{-(c)}\end{array}$ & $\begin{array}{c}\text { соответствие } \\
\text { увеличения } r^{+(c)}\end{array}$ \\
\hline $\begin{array}{c}X_{3} \\
\text { Получение сырья на производство }\end{array}$ & $\begin{array}{c}E_{2} \\
\text { Сырье, отпущенное на } \\
\text { производство за период } T\end{array}$ & $\begin{array}{c}E_{3} \\
\text { Производство (цех 1) }\end{array}$ \\
\hline $\begin{array}{c}X_{4(1)} \\
\text { Выпуск полупродукта (цех 1) }\end{array}$ & \multirow{4}{*}{$\begin{array}{c}E_{2} \\
\text { Сырье, отпущенное на } \\
\text { производство за период } T\end{array}$} & $\begin{array}{c}A_{3} \\
\text { Полупродукт (цех 1) }\end{array}$ \\
\hline $\begin{array}{c}X_{4(2)} \\
\text { Списание сырья на отходы (цех 1) }\end{array}$ & & $\begin{array}{c}B_{3} \\
\text { Безвозвратные отходы } \\
(\text { цех 1) }\end{array}$ \\
\hline $\begin{array}{c}X_{4(3)} \\
\text { Списание сырья на брак (цех 1) }\end{array}$ & & $\begin{array}{c}C_{3} \\
\text { Брак (цех 1) } \\
\end{array}$ \\
\hline $\begin{array}{c}X_{4(4)} \\
\text { Инвентаризация сырья в незавершен- } \\
\text { ном производстве (цех 1) }\end{array}$ & & $\begin{array}{c}C_{3} \\
\text { Незавершенное произ- } \\
\text { водство (цех 1) }\end{array}$ \\
\hline $\begin{array}{c}X_{4} \\
\text { Выпуск (оприходование) } \\
\text { полупродукта } \\
\end{array}$ & $\begin{array}{c}E_{3} \\
\text { Производство (цех 1) }\end{array}$ & $\begin{array}{c}E_{4} \\
\text { Производство (цех 2) }\end{array}$ \\
\hline$\ldots$ & $\ldots$ & $\ldots$ \\
\hline $\begin{array}{c}X_{5} \\
\text { Выпуск готовой продукции }\end{array}$ & $\begin{array}{c}E_{4} \\
\text { Производство (цех 2) }\end{array}$ & $\begin{array}{c}E_{5} \\
\text { Готовая продукция }\end{array}$ \\
\hline
\end{tabular}

Вторая задача - определение эквивалентных и неэквивалентных подмножеств при отображении данных среднего уровня $x\left(n_{s}^{(c)}\right)$ и $\quad x\left(n_{s+1}^{(c)}\right) \quad$ множеств параллельнопоследовательных операций $\quad X_{s-1}^{s}\left(N_{s}\right) \quad$ и $X_{s}^{s+1}\left(N_{s+1}\right)$ двух видов (или подвидов, рисунок 5), между которыми существуют отношения соответствия к множеству объектов учета $E_{s}\left(N_{s}\right)$ за период проверки $T$.

\section{Выводы:}

1. Определены структурные элементы информационной модели предметной области: данные, характеризующие множества объектов и операций.

2. По функциональному назначению выделены два вида взаимосвязей между элементами предметной области среднего уровня, подчиненные правилам предпосылки, ко(C) Т. В. Нескородева, 2020 DOI: $10.24025 / 2306-4412.2 .2020 .194985$ торые формализованы в виде графов отношений соответствия.

3. Сформированы функциональные структуры преобразований данных в виде последовательностей (многослойных графов) двух видов отображений. Первый - между множествами значений характеристик параллельно-последовательных операций, второй между множествами значений характеристик взаимосвязанных объектов. Это позволило определить, что проверку предпосылки «Полнота» можно декомпозировать на проверку эквивалентности двух видов отображений, выделенных выше.

4. Выполнены постановки задач подсистемы аудита предпосылки среднего уровня ИТ СППР в виде задач определения эквивалентных и неэквивалентных подмножеств при двух видах отображений обобщенных показателей среднего уровня. 


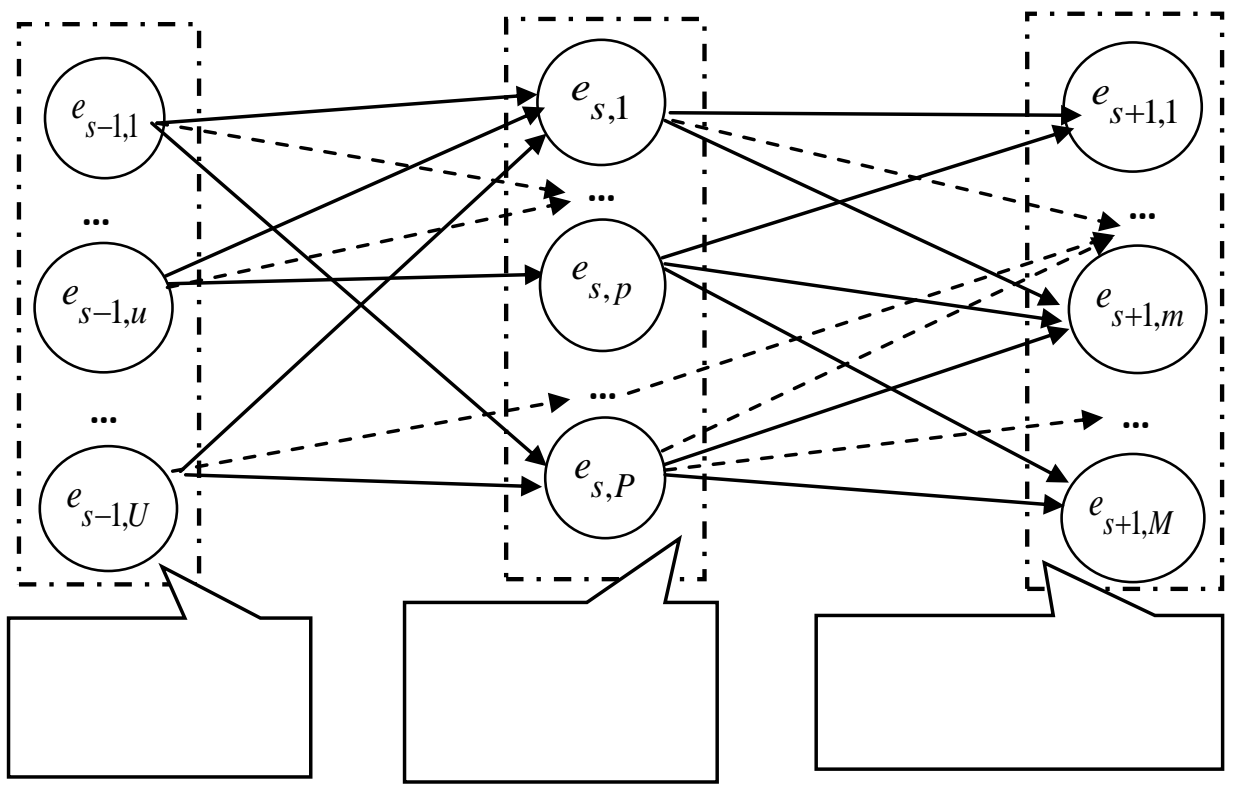

Рисунок 4 - Граф $G_{4}^{(c)}$ отображений данных множеств объектов учета по подвидам

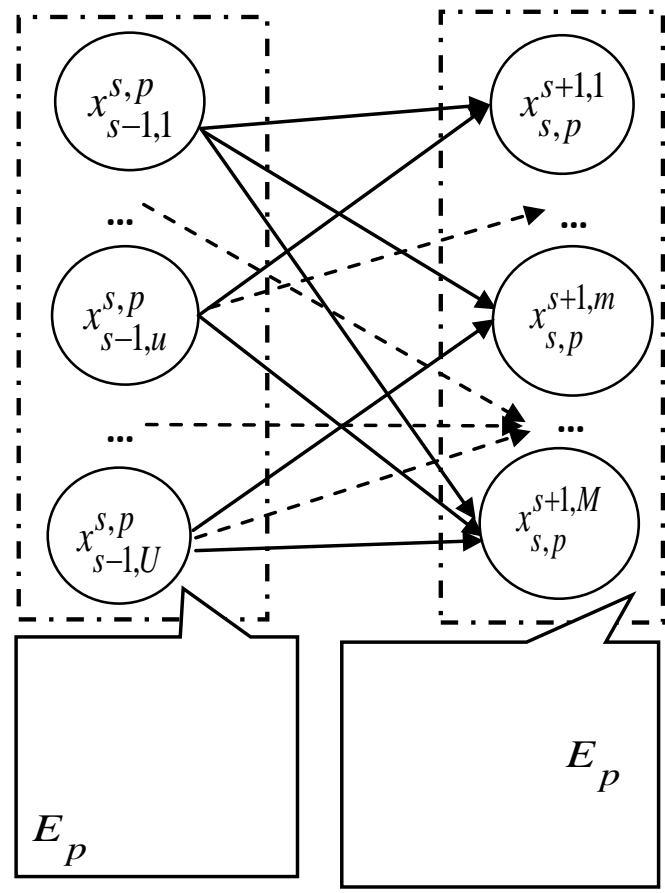

Рисунок 5 - Граф $G_{5}^{(c)}$ отображений данных множеств последовательно-параллельных операций за период $T$ по подвидам (средний уровень)

Перспективы дальнейших исследований. Дальнейшие исследования предполагают разработку методик выявления эквивалентных и неэквивалентных множеств при отображениях. Это позволит решать задачи выявления проверки правил предпосылки «Полнота» данных множеств при отображе-

(C) Т. В. Нескородева, 2020

DOI: $10.24025 / 2306-4412.2 .2020 .194985$ ниях 1-го типа: получено сырье - выпущен полупродукт, получен полупродукт - выпущена готовая продукция и 2-го типа: выпущен полупродукт - получен полупродукт, выпущена продукция - оприходована продукция.

\section{Список использованных источников}

[1] Xinli Hu, "Effectiveness of information technology in reducing corruption in China", Electronic Library, vol. 33, iss. 1, pp. 52-64, 2015 , doi: 10.1108 / el-11-2012-0148.

[2] С. В. Ивахненков, Информационные технологии аудита и внутрихозяйственного контроля в контексте мировой интеграциии: монография. Житомир: Рута, 2010.

[3] E. Kirkos, C. Spathis, and Y. Manolopoulos, "Data mining techniques for the detection of fraudulent financial statement", Expert Syst. Appl., vol. 32, iss. 4, pp. 995-1003.9, 2007.

[4] J. Dai, and M. A. Vasarhelyi, "Imagineering Audit 4.0", Journal of Emerging Technologies in Accounting, no. 13 (1), pp. 1-15, 2016.

[5] С. А. Яремко, та В. В. Коваленко, "Дослідження проблем впровадження сучасних інформаційних систем аудиту в контрольно-ревізійній діяльності", Комп ютерноінтегровані технології: освіта, наука, виробництво, № 14, с. 179-182, Луцьк, 2014.

[6] Jarrod West, M. Bhattacharya, and R. Islam, "Intelligent financial fraud detection practices: a comprehensive review", Computers \& Security, vol. 57, pp. 47-66, 2016, doi: 10.1007 / 978-3-319-23802-9_16 
[7] Chi-Chen Lin, An-An Chiu, Shaio Yan Huang, and David C. Yen., "Detecting the financial statement fraud: the analysis of the differences between data mining techniques and experts' judgments", KnowledgeBased Systems, no. 89, pp. 459-470, 2015, doi: $10.1016 /$ j.knosys.2015.08.011.

[8] A. Mohiuddin, Abdun Mahmooda, and Islam Rafiqul, "A survey of anomaly detection techniques in financial domain", Future Generation Computer Systems, no. 55, pp. 278288, 2016, doi: 10.1016/j.future.2015.01.001.

[9] А. Бююль, и П. Цёфель, SPSS: Искусство обработки информачии. Анализ статистических данных и восстановление скрытых закономерностей: пер. с нем. СПб: ДиаСофтЮП, 2005.

[10] М. 3. Згуровский, и Н. Д. Панкратова, Системный анализ: Методология. Проблемы. Приложения: монография. 2-е изд., перераб. и доп. Киев: Наук. думка, 2016.

[11] Е. А. Андренко, и С. М. Мордовцев, "Методика атрибутивного выборочного исследования в аудите", Бизнес Информ, № 2, c. 200-203, 2013.

[12] Т. В. Нескородева, "Правила и составные части методики обобщенно-множественного отображения информации в подсистеме аналитического учета СППР аудита верхнего уровня", Вісник НТУ «ХПІ». Серія: Системний аналіз, управління та інформаційні технології, № 55 (1276), с. 31-38, Харків: НТУ «ХПІ», 2017.

[13] Т. В. Нескородева, "Постановка елементарних задач аудиту передумови положень бухгалтерського обліку в інформаційній технології системи підтримки рішень", Сучасні інформаційні системи, т. 3, № 1, c. 48-54, 2019. ISSN 25522 9052, doi: 10.20998/2522-9052.2019.1.08.

\section{References}

[1] Xinli Hu, "Effectiveness of information technology in reducing corruption in China", Electronic Library, vol. 33, iss. 1, pp. 52-64, 2015, doi: 10.1108 / el-11-2012-0148.

[2] S. V. Ivakhnenkov, Information technologies of the audit and internal control in the context of world integration: monograph. Zhitomir: Ruta, 2010 [in Russian].
[3] E. Kirkos, C. Spathis, and Y. Manolopoulos, "Data mining techniques for the detection of fraudulent financial statement", Expert Syst. Appl., vol. 32, iss. 4, pp. 995-1003.9, 2007.

[4] J. Dai, and M. A. Vasarhelyi, "Imagineering Audit 4.0", Journal of Emerging Technologies in Accounting, no. 13 (1), pp. 1-15, 2016.

[5] S. A. Jaremko, and V. V. Kovalenko, "Investigation of the problems of implementation of modern information audit systems in the control and audit activity", Komp'juterno-integhrovani tekhnologhiji: osvita, nauka, vyrobnyctvo, no. 14, pp. 179182, Lucjk, 2014 [in Ukrainian].

[6] Jarrod West, M. Bhattacharya, and R. Islam, "Intelligent financial fraud detection practices: a comprehensive review", Computers \& Security, vol. 57, pp. 47-66, 2016, doi: 10.1007 / 978-3-319-23802-9_16

[7] Chi-Chen Lin, An-An Chiu, Shaio Yan Huang, and David C. Yen., "Detecting the financial statement fraud: the analysis of the differences between data mining techniques and experts' judgments", KnowledgeBased Systems, no. 89, pp. 459-470, 2015, doi: 10.1016 /j.knosys.2015.08.011.

[8] A. Mohiuddin, Abdun Mahmooda, and Islam Rafiqul, "A survey of anomaly detection techniques in financial domain", Future Generation Computer Systems, no. 55, pp. 278-288, 2016,

doi: 10.1016/j.future.2015.01.001.

[9] A. Bjujulj, and P. Cëfelj, SPSS: The art of information processing. Analysis of statistical data and restoration of hidden patterns: transl. from German. St. Petersburg: DiaSoftJuP, 2005 [in Russian].

[10] M. Z. Zhurovs'kyy, and N. D. Pankratova, System analysis: Methodology. Problems. Applications: monograph. 2nd ed., revised and suppl. Kiev: Nauk. dumka, 2016 [in Russian].

[11] E. A. Andrenko, and S. M. Mordovtsev, "Methods of attributive sampling research in audit", Biznes Inform, no. 2, pp. 200-203, 2013 [in Russian].

[12] T. B. Neskorodeva, "Rules and components of the method of generalized-multiple display of information in the express analysis subsystem of the audit decision support system", Visnyk NTU «KhPI». Serija: Systemnyj analiz, upravlinnja ta informacijni tekhnologhiji, no. 55(1276), pp.31-38, Kharkiv: NTU «KhPI», 2017 [in Russian]. 
[13] T. B. Neskorodeva, "Formulation of elementary audit tasks of accounting provisions prerequisite in information technology of decision support system", $\mathrm{Su}$ - chasni informacijni systemy, vol. 3 , no. 1, pp. 48-54, 2019 [in Ukrainian]. ISSN 25522 9052, doi: 10.20998/2522-9052.2019.1.08.

T. V. Neskorodieva, Ph. D., associate professor, head of the department

e-mail: t.neskorodieva@donnu.edu.ua

Vasyl Stus Donetsk National University

600-richya str., 21, Vinnytsia, Ukraine

\section{STATEMENT OF TASKS OF THE PREREQUISITE AUDIT SUBSYSTEM AT IT DSS MIDDLE LEVEL}

Currently, an urgent scientific and technical problem of information technologies in financial and economic sphere consists in the automation of the analysis of large amounts of financial and economic information data of enterprises stored and received online in the database of local and global computer systems in order to formulate recommendations for decision-making during audits. In previous works the author formed a methodology for generalized-multiple data display in the express audit subsystem of the prerequisite "Correspondence of expenses and income" at the middle level. In the case of identifying nonequivalent subsets of data, the system switches (through the decision maker) to the audit subsystem "Completeness". To implement this technique, when checking the prerequisite "Completeness", it is necessary to present the functional structure of data transformations of the middle level in the form of sequences of mappings of sets and distinguish subtasks.

The article considers the problem of setting objectives for audit subsystems of the prerequisites of the Regulations (standards) of accounting at IT DSS as components of the generalized-multiple display of information. Two types of structural elements of mid-level audit that are invariant with respect to the characteristics of the enterprise are distinguished: sets of objects and operations. This allows to determine structural elements of the information model of the subject area: data characterizing sets of objects and data characterizing sets of operations. Two types of relationships between the elements of the subject area which subject to the rules of the prerequisite, formalized in the form of graphs of relationships, are determined. The first one is between two sets of series-parallel operations, the second one is between two sets of objects interconnected by a set of parallel operations. This makes possible to present the functional structure of data sets transformations in the form of a sequence of mappings, subject to the rules of the prerequisite.

Two types of mappings according to their functional purpose are distinguished. The first one characterizes the data transformation at the accounting subsystem for objects set. The second one characterizes the data transformation during data transfer between subsystems. The functional features of accounting for the relationships forming the display data are determined. Two types of elementary sub-tasks of the audit of the prerequisite are distinguished. This allows to decompose the task of automating the prerequisite verification into the problems of checking the equivalence of two types of mappings.

Further studies suggest the development of techniques for identifying nonequivalent data sets with appropriate mappings. This will allow to solve the problem of identifying inconsistencies in these sets in type 1 mappings: raw materials obtained - semi-finished products obtained, semi-finished products obtained - finished products produced; and in type 2 mappings: semi-finished products released - semi-finished products received, finished products released-finished goods capitalized.

Keywords: audit task statement, information technology; audit DSS; sets mapping; middle level. 
Т. В. Нескородсва, к.т.н., доцент, зав. кафедри

e-mail: t.neskorodieva@donnu.edu.ua

Донецький національний університет імені Василя Стуса

вул. 600-річчя, 21, м. Вінниця, 21027, Україна

\section{ПОСТАНОВКА ЗАДАЧ ПІДСИСТЕМИ АУДИТУ ПЕРЕДУМОВИ СЕРЕДНЬОГО РІВНЯ ІТ СППР}

Нині актуальною науково-технічною проблемою інформаційних технологій у фінансовоекономічній сфері є автоматизація аналізу великих обсягів даних фінансово-економічної інформачї підприємств, що зберігаються та надходять у бази даних локальних та глобальних комп ютерних систем з метою сформулювати рекомендації щодо прийняття рімень під час аудиту. У попередніх роботах автора сформовано методику узагальнено-множинного відображення даних у підсистемі експрес-аудиту передумови «Відповідність витрат та доходів» на середньому рівні. У разі виявлення нееквівалентних підмножин даних система переходить у підсистему аудиту «Повнота». Для реалізачії иієї методики при перевіриі передумови «Повноти» необхідно представити функціональну структуру перетворень даних середнього рівня у вигляді послідовностей відображень множин та виділити підзадачі.

У статті розглядається проблема постановки задач підсистеми аудиту передумов Положення (стандартів) бухгалтерського обліку в ІТ СППР як складових методики узагальненомножинного відображення інформащії. Виокремлено два типи структурних елементів аудиту середнього рівня, які є інваріантними щодо характеристик підприємства: множини об'єктів та операцій. Це дозволило визначити структурні елементи інформаційної моделі предметної області: дані, що характеризують множсини об'єктів, $і$ дані, щяо характеризують множини операчій. Визначено два типи зв'язків, між елементами предметної області, що підпадають під дію правил передумови, які формалізуються у вигляді графіків відносин. Периий -між двома множинами паралельно-послідовних операцій, другий - між двома множинами об'єктів, що перетворюються внаслідок множини паралельних операцій. Це дало можливість представити функиіональну структуру перетворень наборів даних у вигляді послідовності відображень, що підпорядковуються правилам передумови.

Виділено два типи відображень за їх функиіональним призначенням. Перший із них характеризує перетворення даних у підсистемі обліку об'єктів. Другий характеризує перетворення даних під час передачі між підсистемами. Виділено два типи елементарних підзадач аудиту передумови. Це дає можливість декомпозувати задачу автоматизаиії перевірки передумови на задачі перевірки еквівалентності двох типів відображень.

Подальші дослідження передбачають розробку методики ідентифікації нееквівалентних множин даних при відображеннях. Це дозволить нам вирішити проблему виявлення невідповідностей цих наборів у відображеннях типу 1: отримана сировина - отримані напівфабрикати, отримані напівфабрикати - вироблена готова продукція; та відображеннях типу 2: випущені напівфабрикати - отримані напівфабрикати, готова продукиія випущена - готова продукиія капіталізуеться.

Ключові слова: постановка задачі аудиту, інформачійна технологія; СППР аудиту; відображення множин; середній рівень.

Стаття надійшла 28.01.2020

Прийнято 10.02.2020

(C) Т. В. Нескородева, 2020

DOI: $10.24025 / 2306-4412.2 .2020 .194985$ 